\title{
Measurement of hand tremor induced by industrial exposure to metallic mercury
}

\author{
R F FAWER, ${ }^{1}{ }^{*}$ Y DE RIBAUPIERRE, ${ }^{2}$ M P GUILLEMIN, ${ }^{1}$ M BERODE, ${ }^{1}$ AND M LOB ${ }^{1}$
}

From the Institute of Occupational Health and Industrial Hygiene, ${ }^{1}$ University of Lausanne, César-Roux 18, 1005 Lausanne, and the Institute of Physiology, ${ }^{2}$ University of Lausanne, Rue du Bugnon, 1011 Lausanne, Switzerland

ABSTRACT Hand tremor due to industrial exposure to metallic mercury vapour was recorded in 26 exposed and 25 non-exposed male workers by an accelerometer attached to the dorsum of the hand. The subjects were instructed to hold the hand and the forearm in the same position first without and then with a load of $1250 \mathrm{~g}$ supported by the hand. Analysis of the records showed that the highest peak frequencies (HPF) (the frequency corresponding to the highest acceleration) were higher in the exposed men than in the controls and were related to the duration of exposure to mercury and to age. The changes in HPF between rest and load were again higher in the exposed men than in the controls and again related to the duration of exposure and to age. The second moment (M2) (an index taking into account the whole recorded spectrum) was similar in the exposed men and controls at rest. The changes in M2 between rest and load were higher in the exposed men than in the controls but were related to duration of exposure and to the biological measurements ( $\log _{e}$ of mercury in urine or blood) and not to age. These neurophysiological impairments might result from the tendency of metallic mercury to accumulate in the cerebellum and the basal ganglia. These results are consistent with the hypothesis that metallic mercury, even at concentrations probably below the current TLV-TWA of $0.05 \mathrm{mg} / \mathrm{m}^{3}$, can lead to neurological disorders.

The most consistent and pronounced effects of exposure to elemental mercury vapour are on the central nervous system (CNS). The first group of effects consists of a neuropsychiatric complex known as "erethism," which includes insomnia, loss of appetite, excessive shyness, and emotional instability. The second effect is a tremor that initially affects the hands and may spread to other parts of the body. The tremor is of the intention type, completely subsiding during sleep, hardly noticeable at rest, and triggered by voluntary use of the affected muscle. ${ }^{12}$ Intention tremor is the most frequently reported sign of excessive exposure to mercury. ${ }^{3}$

The tremors are conveniently recorded by some form of mechanical device measuring either displacement, velocity, or acceleration; the tremor

Requests for reprints to: R F Fawer.

* Present address: Occupational Health and Industrial Hygiene Service, Bellevaux 51, 2000 Neuchâtel, Switzerland.

Received 7 May 1982

Accepted 23 July 1982 signals may then be subjected to Fourier transformation to obtain a spectral analysis. ${ }^{4}$

The objectives of the present investigation were, firstly, to develop a convenient method of analysis of the spectrum of hand tremors at rest and under stress, when an intention tremor would be expected, and, secondly, to relate the results of this analysis to industrial exposure to metallic mercury. The first results of this investigation have been presented in part at the 8th French-Swiss meeting at Lyon, 9 June $1979 .^{5}$

\section{Material and methods}

\section{SUBJECTS}

This study included 26 male workers exposed daily to metallic mercury; seven glass blowers in seven fluorescent tube factories, 12 workers in a chloralkali plant, and seven workers from a chemical industry (acetaldehyde production). Twenty-five male workers from the same factories, never occupationally exposed to mercury, formed the control group. Informed consent was obtained after verbal and written explanations. One exposed worker expected 
to take part in the study declined to do so for undefined reasons.

\section{EXPOSURE TO MERCURY}

Personal air sampling was carried out at $0.05 \mathrm{l} / \mathrm{min}$ drawing air through tubes filled with gold coated asbestos. ${ }^{6}$ After thermal desorption, $\mathrm{Hg}$ vapour was analysed by fluorescent spectrometry. ${ }^{7}$ Mercury analysis in night urine samples was carried out by flameless $\mathrm{AAS}^{8}$ and creatinine in urine by an automatic Jaffe method ${ }^{9}$; mercury concentrations in urine $(\mathrm{Hg}-\mathrm{U})$ were subsequently corrected for creatinine. Mercury in whole blood ( $\mathrm{Hg}-\mathrm{B})$ was measured by fluorescent spectrometry after digestion in $\mathrm{HNO}_{3}$ at $150^{\circ} \mathrm{C}$.

\section{HAND TREMOR MEASUREMENTS}

The subject was seated with his right arm supported by an elbow rest that allowed a $90^{\circ}$ elbow angle with the forearm unsupported and the hand supine. An accelerometer (Brüel and Kjaer 4366, weight $28.7 \mathrm{~g}$ ) was fixed to the dorsum of the third metacarpal bone with a cuff. The electrical signals from this accelerometer are proportional to the acceleration; they were amplified (Brüel and Kjaer 2204) and then transformed by Fourier techniques to obtain a spectrum (EMR/Schlumberger 1510-02 Real time spectrum analyser). The frequency range was $0 \cdot 2 \mathrm{~Hz}$ to $51 \cdot 2 \mathrm{~Hz}$ and each frequency band was $0.2 \mathrm{~Hz}$ wide; the acceleration range was 0.0 to $100.0 \mathrm{~mm} / \mathrm{s}^{2}$. The spectrum was recorded on paper and calibration was performed before each test (Brüel and Kjaer 4291). A first measurement was carried out at rest for 80 seconds and a second measurement was performed with a load $(1250 \mathrm{~g})$ attached to the hand for 80 seconds, starting five seconds after attachment of the load to the wrist.

\section{ANALYSIS OF THE RECORDS}

The highest peak frequency (HPF) was the frequency corresponding to the highest acceleration. When more than one peak was shown, the highest has been chosen, provided that it differed from any other peak by more than $1.5 \mathrm{~Hz}$ and by more than $5.0 \mathrm{~mm} / \mathrm{s}^{2}$. When these criteria were not met, no HPF was determined (fig).

In order to take into account so far as possible the whole spectrum, the following moments were defined:

(a) the products of the acceleration by the corresponding frequency for each band from $2 \cdot 0 \mathrm{~Hz}$ to $30.0 \mathrm{~Hz}$ were obtained. Their sum divided by the number of bands has been defined as the first moment (M1). (Ml $\underset{\mathrm{i}=1}{\mathrm{i}} \sum_{=}^{=} a_{\mathrm{i}} \mathrm{f}_{\mathrm{i}} / \mathrm{n}$, where $\mathrm{a}=$ acceleration, $\mathrm{f}=$

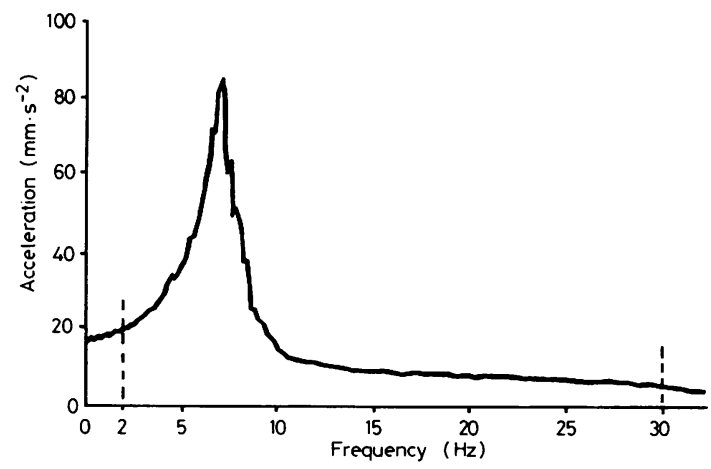

Typical record of tremor at rest. Lower and upper limits of $2.0 \mathrm{~Hz}$ and $30.0 \mathrm{~Hz}$ used for calculation of the moments are shown. Highest acceleration is $85 \mathrm{mms}^{-2}$ and its corresponding highest peak frequency $(H P F)$ is $7.0 \mathrm{~Hz}$.

frequency, $n=$ number of bands, $i=1,2, \ldots, n)$;

$(b)$ the products of the acceleration by the square of the corresponding frequency for each band from $2.0 \mathrm{~Hz}$ to $30.0 \mathrm{~Hz}$ were obtained. Their sum divided by the number of bands has been defined as the second moment (M2). (M2 $\left.\underset{i=1}{i} \sum_{i} a_{i} f_{i}^{2} / n\right)$;

(c) the products of the acceleration by the third power of the corresponding frequency for each band from $2.0 \mathrm{~Hz}$ to $30.0 \mathrm{~Hz}$ were obtained. Their sum divided by the number of bands has been defined as the third moment (M3). (M3 $\left.\stackrel{i}{=} \sum_{i}^{=} a_{i} f_{i}^{3} / n\right)$.

All frequency bands for which the frequency was less than $2.0 \mathrm{~Hz}$ have not been taken into account because of possible interferences from cardiac beats. ${ }^{+}$All those for which the frequency was more than $30.0 \mathrm{~Hz}$ have also not been taken into account because the corresponding accelerations were so low that they may be considered as negligible.

\section{STATISTICS}

Student $t$ tests between crude indices of tremor of exposed and control groups were performed; then multiple regressions including duration of exposure, age, and concentration of $\mathrm{Hg}-\mathrm{U}$ or $\mathrm{Hg}-\mathrm{B}$ were fitted, choosing the one that gave the smallest residual mean square. ${ }^{10}$

\section{Results}

Table 1 shows some general data on the study population. Without matching, the mean ages of the exposed and control groups were similar. The duration of exposure to $\mathrm{Hg}$ was on average $15 \cdot 3$ years, with a wide range from one to 41 years. The 
Table 1 Mean and standard error (in parentheses) of age, duration of exposure, and biological and environmental measurements

\begin{tabular}{|c|c|c|}
\hline & $\begin{array}{l}\text { Exposed } \\
n=26\end{array}$ & $\begin{array}{l}\text { Controls } \\
n=25\end{array}$ \\
\hline $\begin{array}{l}\text { Age (years) } \\
\text { Duration of exposure to } \mathrm{Hg} \text { (years) } \\
\mathrm{Hg} \text { blood }(\mu \mathrm{mol} / l) \\
\mathrm{Hg} \text { urine }(\mu \mathrm{mol} / \mathrm{mol} \text { creatinine })^{*} \\
\text { Personal exposure (TWA) }\left(\mathrm{mg} / \mathrm{m}^{3}\right)^{2} \dagger\end{array}$ & $\begin{array}{ll}44 \cdot 0 & (2 \cdot 3) \\
15 \cdot 3 & (2 \cdot 6) \\
41 \cdot 3 & (3 \cdot 5) \\
11 \cdot 3 & (1 \cdot 2) \\
0.026 & (0 \cdot 004)\end{array}$ & $\begin{array}{l}44 \cdot 6(1 \cdot 8) \\
16 \cdot 6(1 \cdot 6) \ddagger \\
3 \cdot 4(0 \cdot 7)\end{array}$ \\
\hline
\end{tabular}

* average of two determinations

† Three subjects $>0.05 \mathrm{mg} / \mathrm{m}^{3}$ (TLV)

$\ddagger$ Twenty-four subjects only.

relation between $\mathrm{Hg}-\mathrm{U}(\mu \mathrm{mol} / \mathrm{mol}$ creat $)$ and $\mathrm{Hg}-\mathrm{B}$ $(\mu \mathrm{mol} / l)$ was satisfactory $(\mathrm{r}=0.49, \mathrm{n}=50, \mathrm{p}<0.001)$ and not modified by logarithmic transformation.

Table 2 compares the results of HPFs between the exposed and the control groups. It has not been possible to determine HPF under the criteria defined in methods at rest in one exposed and two controls and under load in two exposed and two controls. Thence the slightly smaller population sizes on which comparisons could be made. The upper part of this table shows that the mean HPFs at rest were higher in the exposed men than in the controls. The residual mean squares in the analysis of variance of the multiple regression were the least with only age and duration of exposure (durexp) as predictor variables $\left(\mathrm{F}_{2,45}=\right.$ $5.56, \mathrm{p}<0.01)$. The regression equation was: HPF $(\mathrm{Hz})=8.39-0.039$ (age in years) +0.047 (durexp in years). The inclusion of $\mathrm{Hg}-\mathrm{U}, \mathrm{Hg}-\mathrm{B}$, or their respective logarithms, did not decrease the mean residual squares. The lower part of this table shows the mean changes in HPFs between rest and load. Both exposed men and controls showed statistically significant decreases, the greatest being in the exposed men. The test of difference between exposed men and controls was significant $(t=2 \cdot 65, d f=45, p=0.011)$. Again the residual mean squares in the analysis of variance of the multiple regression were the least with only age and duration of exposure (durexp) as predictor variables $\left(\mathrm{F}_{2,44}=4.08, \mathrm{p}<0.05\right)$. The regression equation was: $\mathrm{HPF}$ change $(\mathrm{Hz})=4 \cdot 37-$ 0.035 (age in years) +0.046 (durexp in years). The three calculated moments were very closely related to each other and the lowest observed correlation coefficient was $r=0.97(n=51)$. Therefore only the results of the second moment (M2) are presented.

Table 3-The upper part indicates that the mean M2s at rest between exposed men and controls did not show any statistically significant difference. The lower part of this table compares the mean changes in M2s between rest and load. The controls did not change significantly whereas the exposed group did.

Nevertheless the test of the difference between changes observed in controls and exposed men was not striking $(\mathrm{t}=1.98, \mathrm{df}=49, \mathrm{p}=0.054)$. The mean residual squares in the analysis of variance of the multiple regression were the least with only duration of exposure (durexp) and $\log _{\mathrm{e}} \mathrm{Hg}-\mathrm{U}$ as predictor variables $\left(\mathrm{F}_{2.48}=5 \cdot 29, \mathrm{p}<0.01\right)$. The regression equation was: M2change $\left(10^{2} \mathrm{~mm} / \mathrm{s}^{4}\right)=-0.42+0.16$ (durexp in years) $+1.07\left(\log _{e} \mathrm{Hg}-\mathrm{U}\right.$ in $\mu \mathrm{mol} / \mathrm{mol}$ creat). Lesser $F$ values were obtained with $\mathrm{Hg}-\mathrm{B}$ instead of $\mathrm{Hg}-\mathrm{U}$.

Table 2 Comparisons between control and exposed groups for highest frequency (SE in parentheses)

\begin{tabular}{|c|c|c|c|}
\hline & No & $\begin{array}{l}\text { Mean } \\
(H z)\end{array}$ & Test of difference \\
\hline $\begin{array}{l}\text { At rest: } \\
\text { Control group } \\
\text { Exposed group }\end{array}$ & $\begin{array}{l}23 \\
25\end{array}$ & $\begin{array}{l}6 \cdot 40(0 \cdot 19) \\
7 \cdot 60(0 \cdot 22)\end{array}$ & Unpaired $\mathrm{t}_{\text {todf }}=4 \cdot 11^{*}$ \\
\hline $\begin{array}{l}\text { Changes between rest and load: } \\
\text { Control group } \\
\text { Exposed group }\end{array}$ & 23 & $\begin{array}{l}2.69(0 \cdot 19) \\
3.62(0 \cdot 29)\end{array}$ & $\begin{array}{l}\text { Paired } \mathrm{t}_{2, \mathrm{df}}=14 \cdot 00^{*} \\
\text { Paired } \mathrm{t}_{2, \mathrm{df}}=12 \cdot 43^{*}\end{array}$ \\
\hline
\end{tabular}

$* \mathrm{p}<0 \cdot(0) 1$.

Table 3 Comparisons between control and exposed groups for second moment (SE in parentheses)

\begin{tabular}{|c|c|c|c|}
\hline & No & $\begin{array}{l}\text { Mean } \\
\left(\mathrm{mm} / \mathrm{s}^{+}\right)\left(10^{2}\right)\end{array}$ & Test of difference \\
\hline $\begin{array}{l}\text { At rest: } \\
\text { Control group } \\
\text { Exposed group }\end{array}$ & $\begin{array}{l}25 \\
26\end{array}$ & $\begin{array}{l}10 \cdot 9(1.1) \\
13.3(0.9)\end{array}$ & Unpaired $t_{d x d f}=1.59$ \\
\hline $\begin{array}{l}\text { Changes between rest and load: } \\
\text { Control group } \\
\text { Exposed group }\end{array}$ & $\begin{array}{l}25 \\
26\end{array}$ & $\begin{array}{l}0.9(1 \cdot 1) \\
4 \cdot 1(1 \cdot 2)\end{array}$ & $\begin{array}{l}\text { Paired } \mathrm{t}_{2 \mathrm{df}}=0 \cdot 90 \\
\text { Paired } \mathrm{t}_{2 \mathrm{sdf}}=3 \cdot 40^{*}\end{array}$ \\
\hline
\end{tabular}

: $\mathrm{p}<(1) \cdot(0) 2$. 


\section{Discussion}

This investigation has shown evidence of differences in the spectrum of hand tremor between workers exposed to metallic mercury and an unexposed control group.

The most important predictor variable of hand tremor was always the duration of exposure. Unfortunately, the histories of exposure to metallic mercury for each individual exposed worker are not well known. There is, however, evidence that in the past the glass blowers have been exposed to higher concentrations of mercury than at the time of the present study. "The chloralkali plant was modified eight years before the investigation and the acetaldehyde production process 15 years before. It appears, therefore, that enough time has elapsed to allow for a new equilibrium in the body burden of mercury. The concentrations of $\mathrm{Hg}-\mathrm{U}$ and $\mathrm{Hg}-\mathrm{B}$, however, were somewhat related to the duration of exposure $\left(\log _{\mathrm{e}} \mathrm{Hg}-\mathrm{U}\right.$ and durexp : $\mathrm{r}=0.31 ; \mathrm{n}=51, \mathrm{p}<$ 0.05; $\log _{\mathrm{e}} \mathrm{Hg}-\mathrm{B}$ and durexp : $\mathrm{r}=0.43, \mathrm{n}=50, \mathrm{p}<$ 0.01 ). On the other hand, $\mathrm{Hg}-\mathrm{U}$ and $\mathrm{Hg}-\mathrm{B}$ were also, but to a lesser extent, related to the hand tremor.

Only a multiple regression analysis will allow a disentanglement of the effects of the different predictor variables (age, durexp, $\mathrm{Hg}-\mathrm{U}$, and $\mathrm{Hg}-\mathrm{B}$ ) on the hand tremor.

Age and duration of exposure were the best predictors of HPF and HPF change. Age was negatively related to HPF, and these findings are supported by others. ${ }^{12}$ HPF was sometimes difficult to determine accurately. In the present study dealing with 102 spectra at rest and under load, seven HPFs could not be determined; this proportion is similar to that published by others. ${ }^{12}$

The M2 change was no better related to the predictor variables than HPF. On the other hand, the moments could always be determined. The best predictor variable was duration of exposure but associated with $\log _{\mathrm{e}} \mathrm{Hg}-\mathrm{U}$. This set of variables appears more sensitive than the one (durexp and age) shown for HPF; the effect of age was negligible. Hg-B and its logarithm appeared to be a weaker predictor than $\mathrm{Hg}-\mathrm{U}$. No explanations could be given for this finding which is, however, consistent with the results of others. ${ }^{13}$

Comparisons with other studies are difficult because of the different methods used. Kazantzis, in a working paper for the conference on MAC values in Stockholm $1968,{ }^{*}$ estimated the finger tremor by an integrator counter that gave a numerical score (= counts). The results showed higher mean counts in 17

${ }^{*}$ Reprint requests to: Institute of Hygiene, Karolinska, S-10401, Stockholm 60, Sweden. exposed workers than in 41 controls, but no pronounced association was noticed between tremor counts and the most recent urinary mercury figure; no spectral analysis was carried out.

Chaffin and Miller ${ }^{13}$ recorded the tremor in 77 exposed workers and 68 controls by a force sensing transducer attached to a $6.8 \mathrm{~kg}$ load supported by the wrist. Their mean $\mathrm{Hg}$-Bs were similar to those of the present study and their results showed an association between the forearm tremor frequency, as determined by power spectrum analysis, and the $\log _{\mathrm{e}}$ of the urinary mercury excretion. No indication is given on the relation with duration of exposure or other possible predictor variables. It appears, however, that these results support our findings of increasing HPF with increasing body burden of mercury.

In another study the same group ${ }^{14}$ recorded the tremor in 79 exposed workers and 51 controls. The exposure level was less than in the above study as indicated by their respective mercury urine concentration. With the loading of $6.8 \mathrm{~kg}$ as described above, no relationship was shown between frequency of forearm tremor and excretion of urine mercury. Under much lighter loading $(285 \mathrm{~g})$ the percentage of neuromuscular tremor power appeared to be related to urine mercury, the number of peak levels exceeding $0.5 \mathrm{mg} / \mathrm{l}$ in the previous 12 months being the most important predictor. These different results apparently due to different loadings might have the following physiological explanation.

The subject is requested to hold the forearm and the hand in the same position, with or without loading. This task is easy to perform and therefore a first good approximation could be to consider the upper extremity as a passive mass spring system that has a natural frequency $f^{4} ; f=\sqrt{k / m}$, where $k=$ spring stiffness and $\mathrm{m}=$ mass. ${ }^{*}$ If the mass is doubled $\mathrm{k}$ must then also be doubled to hold the same position ( $\mathrm{k} \equiv$ $\mathrm{F} / l$ where $l=$ spring elongation and $\overrightarrow{\mathrm{F}}=\dot{\mathrm{m}} \overrightarrow{\mathrm{g}}$, where $\overrightarrow{\mathrm{g}}$ $=$ gravitation). Therefore $f=\sqrt{2 k / 2 m}=\sqrt{k / m}$. The natural frequency will remain the same provided the passive mass spring system is not influenced by activity of the central nervous system.

When the added mass is heavy, all muscle fibres are recruited and they approach their tetanic fusion frequency. In this situation all tremor activities generated by the central nervous system are dampened, ${ }^{+}$and the system acts as a passive mass spring. Hence no differences could be expected between exposed workers and controls.

When the added mass is light, only some muscle fibres will be recruited and any defect in the tremor activities generated by the central nervous system will

* $m$ is an equivalent mass of the arm and the load; $k$ is an equivalent stiffness of muscle contraction. 
be more difficult to dampen. It is well known that metallic mercury accumulates in the cerebellum and in the basal ganglia. ${ }^{15}$ It has also been shown that a perturbation of these brain structures may lead to an intention tremor. ${ }^{4}$ With light loadings, the "intoxicated" central nervous system of the mercury exposed workers is not expected adequately to control the amount of tremor generated by the added mass. A shift of spectrum should thus be observed in exposed workers but not in controls.

The present study (see table 3) provides evidence of a shift in moments between rest and load in exposed workers but not in controls. Moreover, these findings are supported by the results of Langolf $\mathrm{et} \mathrm{al}^{14}$ who showed differences in percentage of neuromuscular power between exposed workers and controls under light loading but not under heavy loading.

The findings of this investigation, supported by the results of others, are consistent with the hypothesis that metallic mercury, even at concentration very probably below the current TLV of $0.05 \mathrm{mg} / \mathrm{m}^{3}$ (see table 1) can lead to neurological disorders. ${ }^{16}$ Follow up studies, ${ }^{1314}$ which have already shown that with lesser exposure the average tremor frequency returned to values closer to normal means, also support our results.

Only one author ${ }^{17}$ found no difference in tremor between exposed workers and controls. The analysis of the results of tremor frequencies, however, appears to be defective because all frequencies up to 7 $\mathrm{Hz}$ were discarded.

The clinical significance of these investigations is difficult to assess. Contrary to the conclusions of the study of Schuckmann, ${ }^{17}$ however, it is believed that these findings might provide some evidence for the necessity for improved working conditions.

We are most grateful to the safety and medical officers for their help in the organisation of the study. We are particularly indebted to Professor M J R Healy, professor of medical statistics, London School of Hygiene and Tropical Medicine, for his advice in the statistical analysis of the data.

\section{References}

' Gerstner BG, Huff JE. Clinical toxicology of mercury. J Toxicol Environ Health 1977;2:491-526.

${ }^{2}$ Hammond PB, Beliles RP. Mercury. In: Doull J, Klaassen CD, Amdur MO, eds. Toxicology. The basic science of poisons. 2nd ed. New York: Macmillan, 1980:421-8.

${ }^{3}$ Battigelli MC. Mercury toxicity from industrial exposure. JOM 1960;2:394-9.

${ }^{4}$ Marsden CD. The mechanisms of physiological tremor and their significance for pathological tremors. In: Desmedt JE, ed. Physiological tremor, pathological tremor and clonus. Progress in clinical neurophysiology. Vol 5. Basel: Karger, 1978:1-16.

${ }^{5}$ Fawer R, de Ribaupierre Y, Lob M. Evaluation du tremblement chez les ouvriers exposés au mercure métallique: résultats préliminaires. Archives des Maladies Professionelles de Médecine du Travail et de Sécurité Sociale 1979:40:1016-9.

- Aubort JD, Rollier H, Ramuz A. Dosage de traces de mercure dans l' atmosphère. Travaux de Chimie Alimentaire et d'Hygiene 1977;68:155-61.

'Thompson KC, Reynolds GD. The atomic-fluorescence determination of mercury by cold vapour technique. Analyst 1971;96:771-5.

${ }^{8}$ Hatch WR, Ott WL. Detection of submicrogram quantities of mercury by atomic absorption spectrophotometry. Analytical Chemistry 1968;40:2085-7.

${ }^{9}$ Zender R, Falbriand A. Analyse automatique de la créatinine dans le sérum et dans l'urine. Clin Chim Acta 1965;12:183-90.

${ }^{10}$ Armitage P. Statistical methods in medical research. Oxford: Blackwell, 1971.

" Lob M. Intoxications chroniques par le mercure dans l'industrie des tubes luminescents. Archives des Maladies Professionnelles de Médecine du Travail et de Sécurité Sociale 1965;26:289-92.

${ }^{12}$ Marsden CD, Meadows JC, Lange GW, Watson RS. Variations in human physiological finger tremor with particular references to changes with age. Electroencephalogr Clin Neurophysiol 1969;27:169-78.

${ }^{13}$ Chaffin DB, Miller JM. Behavioral and neurological evaluation of workers exposed to inorganic mercury. In: Xintaras C, ed. Behavioral toxicology. Early detection of occupational hazards. Cincinnati: National Institute for Occupational Safety and Health, 1974:214-39.

${ }^{14}$ Langolf GD, Chaffin DB, Henderson R, Whittle HP. Evaluation of workers exposed to elemental mercury using quantitative tests of tremor and neuromuscular functions. Am Ind Hyg Assoc $J$ 1978;39:976-84.

${ }^{15}$ Wedig J. Early detection of mercurialism. In: Xintaras C, ed. Behavioural toxicology. Early detection of occupational hazards. Cincinnati: National Institute for Occupational Safety and Health, 1974:207-13.

${ }^{16}$ Zedda S, Cirla AM, Ratti R, et al. Mercury hazard in the manufacture of fluorescent lamps. Med Lav 1980;2:187-92.

${ }^{17}$ Schuckmann F. Study of preclinical changes in workers exposed to inorganic mercury in chloralkali plants. Int Arch Occup Environ Health 1979;44:193-200. 